\title{
О.А.Ланчава
}

\section{МЕТОДИКА МАТЕМАТИЧЕСКОГО МОДЕЛИРОВАНИЯ МАССОПЕРЕНОСА В ГОРНОМ МАССИВЕ}

Как известно, процесс массопереноса в горной массиве описывается дифференциальным уравнением фурье о частным производным /1/.

$$
\frac{\partial \theta}{\partial \tau}=a_{m} \dot{\nabla}^{2} \theta+a_{m} \delta_{\theta} \nabla^{2} t
$$

при следующих краеных условиях:

$$
\begin{aligned}
\tau & =0 ; R=R_{0} ; \theta=\theta_{0}, \\
\tau & =0 ; R-\infty ; \theta-\theta_{0}, \\
\tau>0 ; R & =R_{0} ;-\lambda_{m} \frac{\partial \theta}{\partial R}-\lambda_{m} \delta_{\partial} \frac{\partial t}{\partial R}+\alpha_{m}\left(\theta_{c \bar{m}}-\theta_{b}\right)=0,
\end{aligned}
$$

где $\theta, \mathrm{t}$ - соответственно значение потенциала массоперенооа и температуры горного массива, Дж/моль, - время протекания массообменного процесса, коэффициент потенциалопроводности массопереноса для горного массива, м²/ч; $\boldsymbol{\nabla}^{2}$ - оператор Лапласса; $\boldsymbol{\delta}$ - термоградиентный коэффициент, Дж/моль, ${ }^{\circ} \mathrm{C} ; \mathrm{R}-$ цилиндрическая координата; $\quad \mathrm{R} 0$ - эквивалентный радиус $\quad$ сечения горной

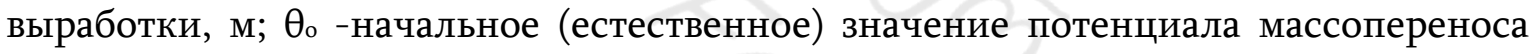
горного массива; $\lambda_{\mathrm{m}}$ - коэффициент массопроводности горного массива; кг.моль/Дж.м.ч.; $\alpha_{m} \quad-\quad$ коэффициент ${ }^{q} \boldsymbol{c} ;$ массопроводности отенок горной

$$
\text { ч; } d_{m}
$$
выработки, кг.моль/Дж.м²ч; $\theta_{\dot{c} \bar{m}}, \theta_{B}$ выработки и рудничного воздуха.

$$
\text { соответственно потенциал массопереноса отенок горной }
$$

$$
\text { Члены в формулах (I) и (4), которые в качестве множителя имеют }
$$
термоградиентный коэффициент $\boldsymbol{\delta}$, показывают эффект термовлагопроводности, т.н. эффект Дюффо. В изотермических условиях эффект Дюффо отсутствует, следовательно, формулы (I) и (4) принимают вид

$$
\begin{gathered}
\frac{\partial \theta}{\partial \tau}=a_{m} \nabla^{2} \theta \\
\tau>0 ; R=R_{0} ;-\lambda_{m} \frac{\partial \theta}{\partial R}+\alpha_{m}\left(\theta_{c \bar{m}}-\theta_{b}\right) \cdot(6)
\end{gathered}
$$


Влагофизические свойства горных пород в зависимости от их.влагосодержания изменяются в широких пределах /2, 3/. Например, для сидеролитов Ткибули-Шаорского каменноугольного месторождения при влагосодержании 0,5\% коэффициент влагопроводности $\lambda_{\mathrm{m}}=1,108 \cdot 10^{-7}$ кг.моль/Дж.м.ч, а при влагосодержании $3 \%$ (максимальное гигроскопическое значение)$\lambda_{\mathrm{m}}=36,355 \cdot 10^{-7}$ кг.моль/Дж.м.ч. T.е. в процессе массообмена указанный коэффициент в среднем изменяется в 32 раза. Для тех же условий коэффициент удельной изотермической массоемкости изменяется 65 раз. При этом коэффициент потенциалопроводности массопереноса меняется на 200\%.

Исходя из вышеизложенного, уравнения (I) и (5) с учетом краевых условий являются существенно нелинейными, в связи о чем их строгое математическое решение связано с непреодолимыми трудностями/4/. Поэтому в подобных случаях прибегают к приближенным методам решения. В данном случае, особо удачным является применение RR -сеток электроинтегратора БУСЭ-70 /5/. Метод решения на интеграторе конечно-разностный, с присущим этому методу приближением. Однако, о изменением геометрического масштаба и масштаба времени, погрешность при приближении можно свести к минимуму и полученные при этом результаты можно с большой достоверностью применять в инженерной практике.

Горный массив на модели имитирует сетка, в узлах которой соеди-нены электрические сопротивления с сосредоточенными параметрами. Электрические параметры сопротивлений соответствуют влагофизическим и временным параметрам натуры, а также условиям влагообмена на границе системы горный массив-рудничшй воздух. Электрические сопротивления интегратора являются регулируемыми, максимальное значение в которых равняется 4,7 МОм.

В данной работе дается методика решения плоских задач нелинейного массопереноса в горном массиве, описываемого дифференциальным уравнением Фурье. В этих задачах горная выработка имеет форму круга, окружающая горная среда которой в радиальном направлении представлена однородной и изотропной породой.

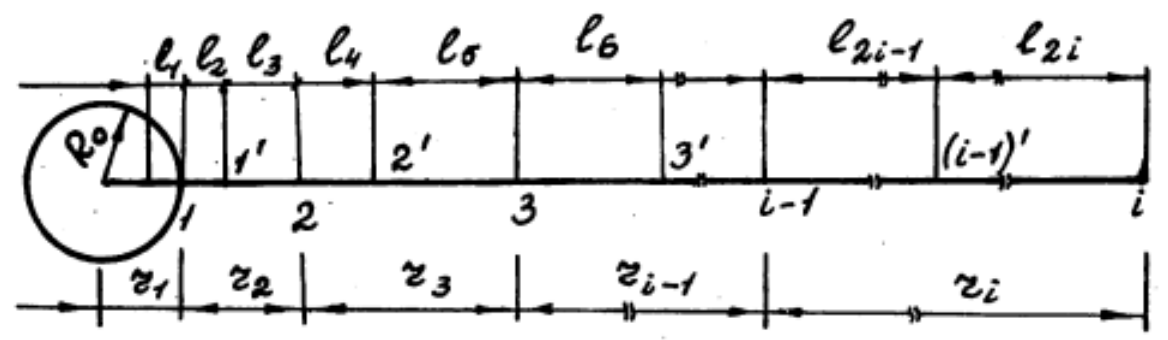

Рис.1 
На рис.1 представлена разбивка окружающего массива на отдельные зоны, которым соответствуют узлы на сетках. Очевидно, что чем меньше расстояние между соседними узлами - $\ell$, т.е. чем меньше длина отдельной зоны в натуре, тем больше точность полученного решения.

C другой стороны, электрическая модель должна имитировать бесконечность массива, т.е. она должна охватывать массив с таким радиусом, дальше которого возмущения естественного поля потенциала массопереноса-не распространяются. Этот радиус практически меняетоя в пределах 200-250 м. Ширина отдельных зон натуры около поверхности горной выработки составляет несколько сантиметров. При увеличении радиуса смоделированного массива указанная ширина прогрессивно растет и в конечных зонах массива составляет 20 и более метров.

Радиус натуры для любой конечной зоны, которому соответствует узел на $\mathrm{RR}$-сетке с сосредоточенными электрическими параметрами можно определить по формуле

$$
\eta_{i}=R_{0}+l_{i}+\ell_{i+1}
$$

$$
\text { где } \ell_{i}, \ell_{i+1} \text { - расстояние между }(i+1) \text { и } i \text { - -ного узла }
$$

соответственно, м.

Следует отметить, что во всех моделях ообладаетоя равенотво $\boldsymbol{Z}_{\boldsymbol{1}}=\boldsymbol{R}_{\boldsymbol{0}}$.

Электрическое сопротивление модели, имитирующей физический эффект коэффициента влагопроводности $\lambda_{\mathrm{m}}$ в натуре, для крайних I -ных узлов определяется по формуле

$$
R_{\lambda_{m i}}^{9}=\frac{\ell_{2 i} R_{N}}{\lambda_{m} r_{i}\left(1+\frac{\ell_{2 i}}{2 r_{i}}\right)}
$$

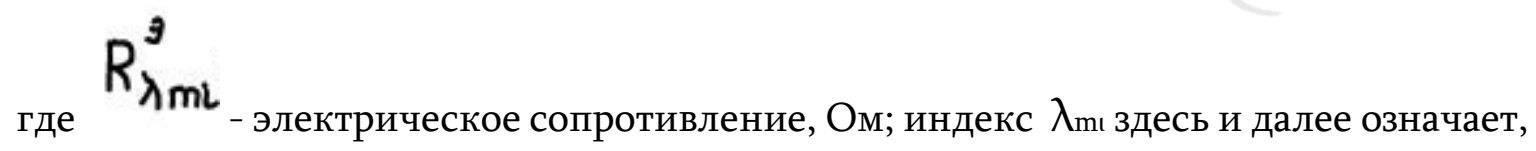
что оно соответствует обратной величине коэффициента влагопроводности натуры в узле í; RN масштаб моделирования Ом.

Для узлов, с .которыми соседствуют другие Узлы, рассчитывается по формуле 


$$
R_{\lambda m i}^{\vartheta}=\frac{\ell_{\left(z_{i}-1\right) R_{N}}}{\lambda_{m} z_{i}\left[1-\frac{l_{\left(z_{i}-1\right)}}{2 \tau_{i}}\right]}+\frac{\ell_{2_{i}} R_{N}}{\lambda_{m} z_{i}\left[1+\frac{\ell_{2 i}}{2 z_{i}}\right]}
$$

Электрическое сопротивление, имитирующее на модели время протекания процесса в натуре для первого и і́ -ного узлов соответственно определяется по формулам

$$
\begin{aligned}
R_{\tau i}^{9} & =\frac{\delta_{\tau} R_{N}}{c_{m} \gamma_{0} \ell_{2} \tau_{1}}, \\
R_{\tau i}^{9} & =\frac{\delta_{\tau} R_{N}}{c_{m} \gamma_{0}\left[\ell_{\left(2_{i}-1\right)}+\ell_{2 i}\right]},
\end{aligned}
$$

где $\delta_{\boldsymbol{\tau}}$ интервал времени, по которому определяется временный масштаб моделирования, ч; $\mathrm{Cm}$ - удельная изотермическая массоемкость горного массива, моль/Дж; $\gamma_{0}$ - плотность горной породы, кг/м².

Граничные условия третьего рода задаются согласно выражению

$$
R_{\alpha m}^{\vartheta}=\frac{R_{N}}{\alpha_{m} \tau_{1}}
$$

При вычислениях по формулам (8) - (12) $\mathrm{R}_{\mathrm{N}}$ является неизвестным, его величина в конце расчета выбиравтоя таким образом, чтобы конечная величина каждого сопротивления не превышала номинал - 4,7 МОм.

Электричеокая модель из $\mathrm{RR}$-резисторов набирается на $R_{\lambda_{\text {mi }}}$ сетках электроинтегратора БУСЭ-70 по координате $\chi$ и в каждый узел подключается временное сопротивление $R_{\tau}^{\vartheta}$. На овободные концы сопротивлений $R_{\tau}^{\text {Э }}$ в начале процесоа осушения $(\tau=0)$ подается $100 \%$ электрический потенциал с помощью делителя напряжения. В дальнейшем, на свободные концы подводятоя напряжения, полученные для соответствующих узлов на предыдущей модели, и так далее, пока не получитоя нужное моделирующее время проветривания.

По мере образования осушезной зоны в массиве вокруг выработки меняются влагофизические свойства горного массива (проявлвние нелинейной задачи) и, следовательно, меняются соответствующие электрические параметры на модели. 
Через каждый интервал времени необходимо производить корректировку сопротивлений, имитирующих эффект влагофизических коэффициентов. Новые, скорректированные, сопротивления в узлах будут соответствовать новым значениям этих коэффициентов, т.е. значениям, которые влагофизические свойства горных пород принимают в процессе сушки.

По предложенной методике были решены практические задачи изотермического и неизотермического массопереноса в системе горный массиврудничный воздух для шахт Ткибули-Шаорского каменноугольного месторождения.

\section{Литература}

1. А.В.Лыков. Тепломаосообмен. - М., Энергия, 1980.

2. О.А.Ланчава, Ю.Р.Ксоврали. Материалы научно-технической конференции "Проблемы наук о Земле". - Тбилиси, 1978.

3. Ш.И.Ониани, Ю.Р.Ксоврели. Труды Международного горного конгресса. Катовице, 1981.

4. Дж.Метьюз, Р.Уокер. Математические методы физики. - М., Атом.издат, 1972.

5. Л.А.Коздоба. Электрическое моделирование явлений тепло- и массоперенооа. - М., Энергия, 1972. 